\title{
Pregnancy in Congenital Heart Diseases
}

\author{
Shweta Bakhru ${ }^{1}$ \\ ${ }^{1}$ CARE Hospital, Hyderabad, Telangana, India
}

\begin{abstract}
Address for correspondence Shweta Bakhru, DNB (Ped), FNB (Ped Cardiology), Pediatric Cardiologist, Care Hospital, Banjara Hills, Hyderabad 500034, Telangana, India (e-mail: hrehaan2015@gmail.com).
\end{abstract}

\begin{abstract}
Keywords

- cardiovascular risk

- congenital heart

disease

- pregnancy

Congenital heart diseases (CHDs) affect 0.8 to $1.5 \%$ of general population. With increase in awareness and medical services, more number of patients with CHDs have entered into adulthood. One of the peculiar physiologic changes in women is going through pregnancy. Misconceptions are common in women with CHD. This write-up is to provide some brief information about CHD patients going through pregnancy. General cardiovascular risk and individual disease-related risks are discussed.
\end{abstract}

Congenital heart disease (CHD) is one of the most common birth defects. ${ }^{1-4}$ It affects 0.8 to $1.5 \%$ of the general population. ${ }^{5-7}$ With increase in awareness and medical services, more number of patients with CHDs have entered into adulthood. One of the physiologic changes in women is going through pregnancy. Misconceptions are common in CHD women. Structured, preconception evaluation and appropriate management are essential to avoid morbidity and mortality. This write-up is an attempt to provide brief information about CHD patients going through pregnancy.

\section{Physiologic Implication of Pregnancy on Cardiovascular System}

During pregnancy, to accommodate increase in blood volume, changes in cardiac output, heart rate, and systemic and pulmonary vascular resistance occur. These changes vary during antenatal, natal, and postnatal periods. Usually these hemodynamic burdens are well tolerated in women without CHD.

Hemodynamic changes during pregnancy and postpartum period are studied by Robson et al. ${ }^{8-13}$ There is increase in stroke volume, heart rate, and cardiac output as early as fifth week of gestational age. It persistently increases throughout pregnancy, ${ }^{8,13}$ whereas systemic vascular resistance starts dropping from fifth week of gestational age till the end of the second trimester. It starts incrementing from 32 weeks onward till term and can reach beyond prepregnancy state. ${ }^{8,9,12-14}$ Treating physician must have adequate knowledge of these changes while encountering CHD women.
Physiologic changes impose burden on cardiovascular system in a compromised heart.

\section{Risk Assessment and Stratification for Adverse Maternal and Fetal Complication}

In general, the risk factors listed in - Tables $\mathbf{1}$ and $\mathbf{2}$ are considered to be potential for adverse maternal and neonatal complications. ${ }^{19}$

The first four risk factors listed in - Table $\mathbf{1}$ belong to CARPREG (Cardiac Disease in Pregnancy) risk index. According to CARPREG risk index, 1 point is given to each predictors and risk is classified.

The risk of maternal cardiac adverse event with zero risk factor is $<5 \%$, with one risk factor is $27 \%$ and more than one risk factor being $75 \%$.

\section{Multidirectional Consideration}

Often, tertiary care is required to manage these critical subsets. Psychological and social support is equally important to mothers going through pregnancy. Family and the patient should have detailed information about the risk, natural history, and recurrence chances (-Fig. 1).

Obstetric complications often impose challenge in CHD women. Multiple pregnancies, pregnancy-induced hypertension (PIH), eclampsia, gestational diabetes mellitus (GDM), anemia, and hypercoagulable state are important challenges.

World health Organization (WHO) classification provides another roadmap in assessing maternal cardiovascular risks (-Table 3). 
Table 1 List of potential risk factors in pregnant women (with CHD) for adverse maternal events

1. Poor functional class (NYHA class 3 or 4 ) or cyanosis

2. Systemic ventricle $\mathrm{EF}<40 \%$

3. Mitral valve area $<2 \mathrm{~cm}^{2}$, aortic valve area $<1.5 \mathrm{~cm}^{2}$ or peak left ventricular outflow tract gradient $>30 \mathrm{~mm} \mathrm{Hg}$ (moderate to severe)

4. Prepregnancy cardiac event (symptomatic arrhythmia, stroke, pulmonary edema)

5. Subpulmonic ventricular dysfunction (TAPSE < 16)

6 . Moderate to severe pulmonary regurgitation

7. Mechanical heart valves

8. Moderate to severe atrioventricular valve regurgitation

9. Cyanosis (saturation < 90\%)

10. Natriuretic peptide (NT-proBNP > $128 \mathrm{pg} / \mathrm{mL}$ at $20 \mathrm{wk}$ is predictive of cardiac event)

11. Smoking history

12. Repaired or unrepaired cyanotic heart disease.

13. Lesion-specific risk

Abbreviations: EF, ejection fraction; NT-proBNP, N-terminal pro-brain natriuretic peptide; NYHA, New York Heart Association; TAPSE, tricuspid annular plane systolic excursion.

Table 2 List of risk factors for fetal and neonatal adverse events

1. Poor maternal functional classes 3 and 4 or cyanosis

2. Maternal left heart obstruction

3. Low maternal oxygen saturation

4. Obstetric risk factors and abnormal uteroplacental flow

5. Mechanical prosthetic valve

6 . Maternal cardiac event or decline in cardiac output during pregnancy

7. Tobacco and smoking

8. Anticoagulation therapy, cardiac medication multiple gestation

9. Lesion-specific risk factor

\section{Individual Risk Categorization and Management of Pregnancy with Congenital Heart Diseases}

Congenital heart diseases in adults can be classified into 4 categories ( - Fig. 2 ) as listed below:

1. Simple acyanotic heart disease with shunt lesions

2. Acyanotic obstructive disease

3. Cyanotic heart disease (unoperated or palliative surgery or corrective surgery)

4. Congenital heart diseases with pulmonary artery hypertension

Obstetric implications, neonatal outcomes of individual CHDs are discussed in the following section.

\section{Septal Defects}

1. Repaired and Unrepaired Atrial Septal Defect Maternal Effect

Unoperated atrial septal defect (ASD) is usually well tolerated during pregnancy. Often, ASD is diagnosed during pregnancy due to increase in cardiac output. One of the contraindications to pregnancy with ASD is PAH. Arrhythmia can be seen in uncorrected ASD due to atrial dilation. ${ }^{19-21}$ Repaired ASD without residual lesion and normal ventricular function bear no extra risk during pregnancy.

\section{Obstetric Risk and Management}

Preeclampsia can complicate ASD in the form of increase left-to-right shunt. This increases right ventricular (RV) volume overload. Study done at the Netherlands and Belgium showed that women with an unrepaired ASD are at increased risk of neonatal complication in the form of premature birth and intrauterine growth retardation. ${ }^{21}$

In an uncomplicated ASD, twice follow-up during pregnancy is sufficient. ASD closure during pregnancy is usually not indicated. Care should be taken to prevent paradoxical embolization. Spontaneous vaginal delivery is permissible.

\section{Repaired and Unrepaired Ventricular Septal Defects} Small to moderate unrepaired ventricular septal defects (VSDs) are well tolerated during pregnancy. Large VSD with severe PAH is discussed with PAH section. Repaired VSDs without residual lesion and normal pulmonary artery (PA) pressure can have normal pregnancy outcome. ${ }^{22}$ Normal vaginal delivery can be attempted.

\section{Atrioventricular Septal Defects}

Unrepaired atrioventricular septal defects (AVSDs) with severe PAH is classified under WHO class IV risk assessment. Mild to moderate atrioventricular (AV) valve regurgitation with partial ASD is classified under WHO class II. Severe $\mathrm{AV}$ valve regurgitation can cause cardiac decompensation during pregnancy. Hence it should be surgically repaired prior to conception. Repaired AV canal defect without residual lesion or AV valve regurgitation is tolerated well during pregnancy. ${ }^{23}$

\section{Obstructive Lesions}

\section{Coarctation of Aorta}

Unrepaired severe coarctation of the aorta (COA) is a contraindication and classified under WHO class IV risk assessment. ${ }^{18}$ It is associated with systemic hypertension and possibility of aneurysm formation and dissection. Because of $\mathrm{COA}$, there is a restriction of uterine flow and placental hypoperfusion, which further exaggerate with antihypertensive medications. Hence native COA and residual COA should be treated in advance. Repaired COA patients without residual lesion can have pregnancy. ${ }^{24,25}$

\section{Management}

Blood pressure should be closely monitored. Hypertension may be seen even in absence of residual COA. Residual COA with uncontrolled hypertension might need percutaneous intervention. Risk of dissection is higher. $\beta$ blockers and calcium channel blockers are used for treatment of hypertension. Angiotensin-converting enzyme (ACE) inhibitors are containdicated. Covered stents are advisable to lower risk of dissection. ${ }^{26}$ Spontaneous delivery is preferred in an uncomplicated and treated COA. 


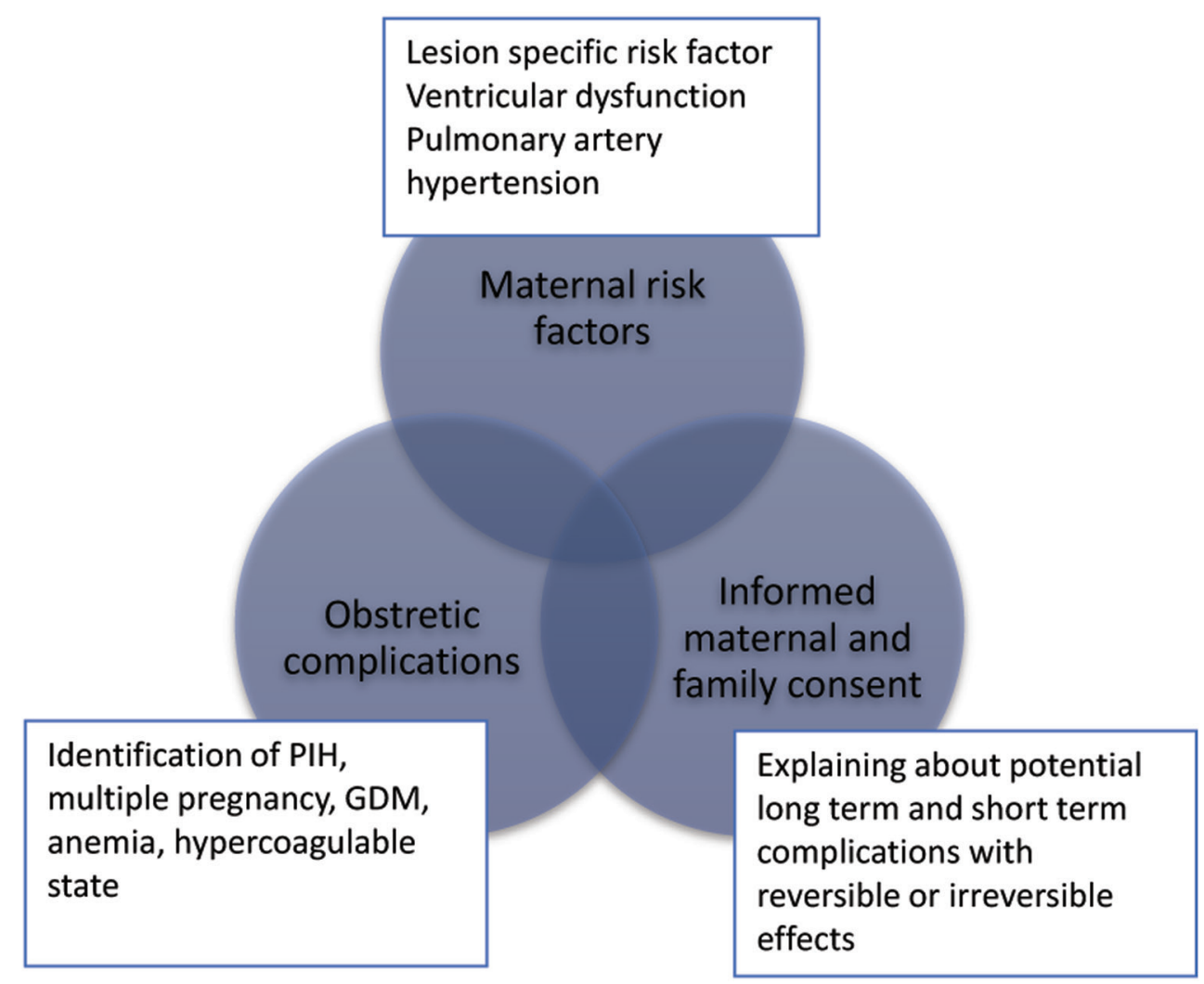

Fig. 1 Multidirectional approach to pregnant woman with CHD. GDM, gestational diabetes mellitus; PIH, pregnancy-induced hypertension.

\section{Pulmonary Stenosis and Pulmonary Regurgitation}

Mild to moderate pulmonary stenosis (PS) is well tolerated during pregnancy. Severe PS at any point of time during pregnancy should be judged with symptoms and RV function. Severe PS should be treated prior to conception. Balloon valvuloplasty should be done in case of severe symptomatic PS. ${ }^{27-29}$

Severe pulmonary regurgitation (PR) can lead to RV dysfunction, and hence it is an independent risk factor for maternal complication. RV dysfunction associated with severe PR should be treated in prior. It is closely associated with arrhythmias. ${ }^{30}$

\section{Management}

Twice during pregnancy, follow-up is satisfactory in case of mild to moderate PS. Balloon valvotomy can be done in case of severe PS detected during pregnancy. ${ }^{29}$ Normal vaginal delivery is possible in case of mild to moderate PS. Cesarean section should be performed in case of New York Heart Association (NYHA) classes III and IV with severe PS.

\section{Aortic Stenosis}

Congenital aortic stenosis (AS) occurs commonly due to bicuspid aortic valve (BAV). BAV is associated with ascending aorta (AAO) dilation.

Aortic valve area less than $1.5 \mathrm{~cm}^{2}$ and left ventricular (LV) outflow tract gradient more than $30 \mathrm{~mm} \mathrm{Hg}$ are associated with adverse maternal event. Exercise testing should be performed in asymptomatic patients before pregnancy to confirm asymptomatic status and evaluate appropriate exercise response.
Pregnancy should be avoided in case of severe AS, LV dysfunction, and inappropriate exercise response..$^{18}$ In severe AS, fetal and maternal mortalities are $30 \%$ and $17 \%$, respectively. Hence it should be treated prior to conception. ${ }^{31}$ Complications are seen predominantly in patients with symptomatic severe AS. ${ }^{32}$

\section{Management}

If severe AS is detected during pregnancy, balloon aortic valvotomy is advised in case of noncalcified valves. Close monthly or bimonthly follow-up is indicated. Cesarean section is indicated in severe AS. Afterload-reducing agents should be avoided during anesthesia. Vaginal delivery is advised in case of mild to moderate AS. AAO size more than $50 \mathrm{~mm}$ should be treated prior to pregnancy.

\section{Cyanotic Heart Diseases}

\section{Tetralogy of Fallot}

This condition should be operated prior to pregnancy. If resting saturation is less than $85 \%$, significant maternal and neonatal complications can be encountered. Maternal complications such as endocarditis, heart failure, and thromboembolism can occur in $30 \%$ of cases and chance of live birth is only $12 \%$. If saturation is more than $90 \%$, chance of fetal outcome improves to $90 \%$. Pregnancy should be discouraged if saturations are less than $85 \% .^{33}$

\section{Postoperative Tetralogy of Fallot}

Postoperative tetralogy of Fallot (TOF) is well tolerated if ventricular function is preserved. Symptomatic patients with PR and ventricular dysfunction can have adverse maternal 
Table 3 WHO classification to assess maternal cardiovascular risks

Pregnancy risk is WHO I (Maternal mortality is not increased. Maternal CER 2.5-5\%)

1. Uncomplicated small or mild PS, PDA, mitral valve prolapse

2. Successfully repaired simple lesions (ASD, VSD, PDA, TAPVC)

3. Isolated atrial or ventricular ectopic beats

Pregnancy risk is WHO II (Small increase in maternal mortality/ moderate increase in morbidity, maternal CER 5.7-10.5\%)

1. Unoperated atrial and small ventricular defects

2. Repaired TOF

3. Most arrhythmias

Pregnancy risk is WHO II-III (Intermediate increase in risk of maternal mortality and moderate to severe increase in morbidity, maternal CER 10-19\%)

1. Mild LV impairment

2. Hypertrophic cardiomyopathy

3. Native or tissue valvular heart disease not considered WHO I or IV

4. Marfan's syndrome without aortic dilation

5. Aorta $<45 \mathrm{~mm}$ in aortic disease with BAV

6. Repaired coarctation

Pregnancy risk is WHO III (Significant increase in maternal mortality and severe morbidity, maternal CER 19-27\%)

1. Mechanical valve

2. Systemic RV with mild ventricular dysfunction

3. Fontan circulation

4. Cyanotic heart disease (unrepaired)

5. Other complex congenital heart disease

6. Aortic dilation 40-45 mm in Marfan's syndrome

7. Aortic dilation $45-50 \mathrm{~mm}$ in aortic disease with BAV

8. Moderate mitral stenosis

9. Severe asymptomatic aortic stenosis

Pregnancy risk WHO IV (Extremely high risk of maternal mortality. Maternal CER 40-100\%)

1. PAH of any cause

2. Severe systemic ventricular dysfunction (LVEF $<30 \%$, NYHA III-IV), systemic RV dysfunction moderate to severe

3. Peripartum cardiomyopathy with LV dysfunction

4. Severe MS and symptomatic aortic stenosis

5. Marfan's syndrome with aorta $>45 \mathrm{~mm}$

6. BAV with aorta $>50 \mathrm{~mm}$, TOF $>50 \mathrm{~mm}$

7. Native severe coarctation

Abbreviations: ASD, atrial septal defect; BAV, bicuspid aortic valve; CER, cardiac event rate; LV, left ventricular/left ventricle; LVEF, left ventricular ejection fraction; MS, mitral stenosis; NYHA, New York Heart Association; PAH, pulmonary artery hypertension; PDA, patent ductus arteriosus; PS, pulmonary stenosis; RV, right ventricular/right ventricle; TAPVC, total anomalous pulmonary venous connection; TOF, tetralogy of Fallot; VSD, ventricular septal defect; WHO, World Health Organization.

outcome. Therefore, pulmonary valve replacement should be performed prior to conception. Arrhythmias and heart failure are noticed in $12 \%$ of population. ${ }^{34}$

\section{Management}

Unoperated TOF patient needs close follow-up. During pregnancy, bedrest and supplemental oxygenation are advised. Compression stockings are advised to prevent venous

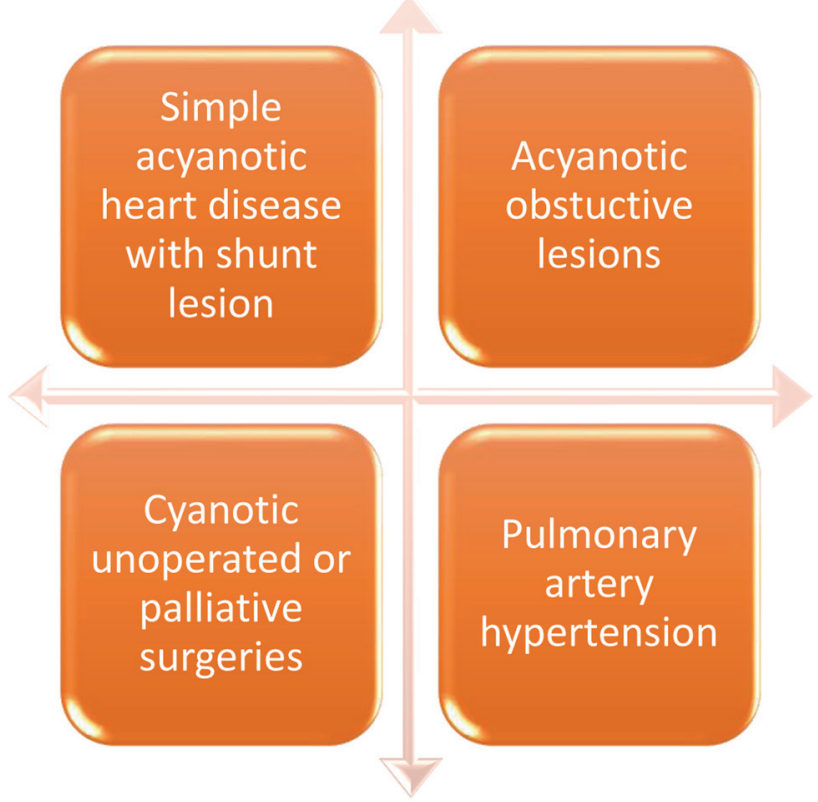

Fig. 2 GDM, gestational diabetes mellitus; PIH, pregnancy-induced hypertension.

stasis, thrombosis, and paradoxical embolization. Low-molecular-weight heparin (LMWH) can be commenced. Good hydration should be maintained. Air filter and endocarditis prophylaxis are advised. In postoperative TOF patients, bimonthly follow-up for ventricular function, functional class, and arrhythmia should be performed.

\section{Transposition of Great Arteries}

Unoperated transposition of great arteries (TGAs) is rare to survive to adulthood but seen in developing countries. Pregnancy is contraindicated in these patients due to possibility of adverse maternal and neonatal event.

\section{Senning or Mustard Surgery}

Pregnancy outcome depends on RV function and tricuspid regurgitation. Pregnancy should be discouraged if functional class is more than 2, more than mild RV dysfunction, and tricuspid regurgitation seen. Heart failure and arrhythmia are seen during pregnancy. ${ }^{35}$

\section{Management}

Heart failure should be treated with diuretics and bedrest. ACE inhibitors are contraindicated. Hydralazine can be given to reduce afterload. In case of RV dysfunction, cesarean section is advised.

Arterial switch surgery: Outcome of pregnancy appears good in cases of postoperative arterial switch surgery. ${ }^{36}$

\section{Ebstein's Anomaly ${ }^{37-39}$}

Ebstein's anomaly is frequently associated with ASD and preexcitation syndrome. Less than severe tricuspid regurgitation and good RV function are favorable toward pregnancy outcome. ${ }^{37}$ Patients can deteriorate due to arrhythmia. Risk of paradoxical embolization exists in presence of ASD. 


\section{Management}

Symptomatic patients with cardiomegaly and severe TR should be treated prior to pregnancy. Severe TR and heart failure, if seen during pregnancy, should be managed with diuretics and bedrest. Wolff-Parkinson-White (WPW) syndrome can be treated with $\beta$-blockers. Digoxin should be avoided in Ebstein's anomaly.

\section{Congenital Corrected Transposition of Great Arteries} Pregnancy outcome largely depends on RV function, symptomatic status, and underlying physiology. Pregnancy should be discouraged in case of RV dysfunction and tricuspid regurgitation. Arrhythmia, irreversible RV dysfunction, and heart failure are noticed during pregnancy. ${ }^{40,41}$

\section{Fontan Surgery ${ }^{42-45}$}

These patients belong to WHO class III-IV in risk assessment and should be counseled carefully. Although successful pregnancies are reported in the literature, cases should be individualized prior to conception. These patients are highly preload dependent, and detailed preconception evaluation is mandatory in form of electrocardiogram (ECG), echocardiography (echo), liver function test, and functional class. Cases with saturation less than $85 \%$, ventricular dysfunction, right ventricle as systemic ventricle, symptomatic status, and with arrhythmia should be discouraged against pregnancy. Often, these patients receive anti coagulation therapy; hence, switch to LMWH is needed. Paradoxical embolization is possible in presence of fenestration. Ventricular dysfunction, arrhythmias, and paradoxical embolization can complicate pregnancy and aid maternal morbidity and mortality.

\section{Management}

Close surveillance is indicated. Anticoagulation is switched to LMWH. ACE inhibitors are contraindicated. If bed rest is advised, compression stockings should be applied to avoid venous stasis. Diuretic might be needed in case of ventricular dysfunction or AV valve regurgitation. Vaginal delivery is preferred. Preload and systemic vascular resistance should be maintained, if cesarean section is required. Offspring risk of premature delivery and fetal death is up to $50 \%$.

\section{Pulmonary Artery Hypertension and Eisenmenger's Syndrome ${ }^{46-49}$}

Pulmonary artery hypertension (PAH) in CHDs can be due to large post-tricuspid shunts or complex cyanotic heart lesions with increased pulmonary blood flow. Unoperated, these conditions cause pulmonary vascular obstructive disease. High maternal mortality is reported up to $50 \%$, predominantly during last trimester and postpartum in women with CHD. Maternal mortality is seen due to PA crisis, pulmonary thrombosis, or refractory RV dysfunction. Reduction in systemic vascular resistance and preload leads to increase in cyanosis.

\section{Management}

Pregnancy is contraindicated. PAH comes under WHO class IV risk factor. If pregnancy occurs, termination is advised. Afterload reduction can occur due to anesthesia that can deteriorate the condition further. Tertiary care center is appropriate to provide best care.

If termination is not possible, patient should be stabilized to maintain adequate cardiac output and saturations. This can be done by maintaining hydration, avoiding acidosis, and systemic vascular resistance. Paradoxical embolization should be prevented by air filter.

Medical therapy such as Bosentan should be continued after explaining the teratogenic risk to the couples. IV prostacyclin, although not available in India, can be used during delivery to provide hemodynamic stability. Appropriate anticoagulation is advocated (LMWH) in selected cases.

\section{Conclusion}

Each case should be individualized and detail evaluation must be performed. Case to case basis risk assessment should be done. Multi modal approach is often warranted. Counselling regarding maternal risk, fetal risk and recurrence chances should be executed. Pregnancy termination is offered if chance of maternal morbidity or mortality exist. Mode of delivery must be planed in advance according to cardiac illness and obstetric indications.

\section{References}

1 Bhide P, Gund P, Kar A. Prevalence of congenital anomalies in an Indian maternal cohort: healthcare, prevention and surveillance implications. PLoS One 2016;11(11):e0166408

2 van der Linde D, Konings E, Slager MA, et al. Birth prevalence of congenital heart disease worldwide: a systematic review and meta-analysis. J Am Coll Cardiol 2011;58(21):2241-2247

3 Egbe A, Uppu S, Lee S, Stroustrup A, Ho D, Srivastava S. Congenital malformations in the newborn population: a population study and analysis of the effect of sex and prematurity. Pediatr Neonatol 2015;56(1):25-30

4 Parker SE, Mai CT, Canfield MA, et al; National Birth Defects Prevention Network. Updated National Birth Prevalence estimates for selected birth defects in the United States, 2004-2006. Birth Defects Res A Clin Mol Teratol 2010;88(12):1008-1016

5 Warnes CA, Liberthson R, Danielson GK, et al. Task force 1: the changing profile of congenital heart disease in adult life. J Am Coll Cardiol 2001;37(5):1170-1175

6 Hoffman JI, Kaplan S. The incidence of congenital heart disease. J Am Coll Cardiol 2002;39(12):1890-1900

7 Lind T. Hamatologic system. Maternal physiology. Washington, DC. CREOG 1985;25:7-40

8 Robson SC, Hunter S, Boys RJ, Dunlop W. Serial study of factors influencing changes in cardiac output during human pregnancy. Am J Physiol 1989;256(4 Pt 2):H1060-H1065

9 Adams JQ, Alexander AM Jr. Alterations in cardiovascular physiology during labor. Obstet Gynecol 1958;12(5):542-549

10 Robson SC, Dunlop W, Boys RJ, Hunter S. Cardiac output during labour. Br Med J (Clin Res Ed) 1987;295(6607): 1169-1172

11 Robson SC, Dunlop W, Hunter S. Haemodynamic changes during the early puerperium. $\mathrm{Br}$ Med J (Clin Res Ed) $1987 ; 2946579: 1065$

12 Karamermer Y, Roos-Hesselink JW. Pregnancy and adult congenital heart disease. Expert Rev Cardiovasc Ther 2007;5(5):859-869 
13 Pirani BB, Campbell DM, MacGillivray I. Plasma volume in normal first pregnancy. J Obstet Gynaecol Br Commonw 1973;80(10):884-887

14 Duvekot JJ, Cheriex EC, Pieters FA, Menheere PP, Peeters LH. Early pregnancy changes in hemodynamics and volume homeostasis are consecutive adjustments triggered by a primary fall in systemic vascular tone. Am J Obstet Gynecol 1993;169(6):1382-1392

15 Siu SC, Sermer M, Colman JM, et al; Cardiac Disease in Pregnancy (CARPREG) Investigators. Prospective multicenter study of pregnancy outcomes in women with heart disease. Circulation 2001;104(5):515-521

16 Silversides CK, Colman JM, Samuel CS. Pregnancy in young women with congenital heart defects. In: Textbook of Moss and Adams Heart Diseases in Infants, Children and Adolescents. 9th ed

17 Martins LC, Freire CMV, Capuruçu CA, Nunes MdoC, Rezende CA. Risk Prediction of cardiovascular complications in pregnant women with heart disease. Arq Bras Cardiol 2016;106(4):289-296

18 Regitz-Zagrosek V, Roos-Hesselink JW, Bauersachs J, et al; ESC Scientific Document Group. 2018 ESC guidelines for the management of cardiovascular diseases during pregnancy. Eur Heart J 2018;39(34):3165-3241

19 Regitz-Zagrosek V, Blomstrom Lundqvist C, Borghi C, et al; European Society of Gynecology (ESG); Association for European Paediatric Cardiology (AEPC); German Society for Gender Medicine (DGesGM); ESC Committee for Practice Guidelines. ESC guidelines on the management of cardiovascular diseases during pregnancy. Eur Heart J 2011;32(24):3147-3197

20 Yap SC, Drenthen W, Meijboom FJ, et al; ZAHARA investigators. Comparison of pregnancy outcomes in women with repaired versus unrepaired atrial septal defect. BJOG 2009;116(12):1593-1601

21 Webb G, Gatzoulis MA. Atrial septal defects in the adult: recent progress and overview. Circulation 2006;114(15):1645-1653

22 Yap SC, Drenthen W, Pieper PG, et al; ZAHARA investigators. Pregnancy outcome in women with repaired versus unrepaired isolated ventricular septal defect. BJOG 2010;117(6):683-689

23 Drenthen W, Pieper PG, van der Tuuk K, et al; Zahara Investigators. Cardiac complications relating to pregnancy and recurrence of disease in the offspring of women with atrioventricular septal defects. Eur Heart J 2005;26(23):2581-2587

24 Vriend JW, Drenthen W, Pieper PG, et al. Outcome of pregnancy in patients after repair of aortic coarctation. Eur Heart J 2005;26(20):2173-2178

25 Beauchesne LM, Connolly HM, Ammash NM, Warnes CA. Coarctation of the aorta: outcome of pregnancy. J Am Coll Cardiol 2001;38(6):1728-1733

26 Ural AV, Caglar IM, Caglar FN, Ciftci S, Karakaya O. Single therapeutic catheterization for treatment of late diagnosed native coarctation of aorta using a covered stent. J Clin Diagn Res 2014;8(3):153-155

27 Hameed AB, Goodwin TM, Elkayam U. Effect of pulmonary stenosis on pregnancy outcomes-a case-control study. Am Heart J 2007;154(5):852-854

28 Hameed A, Karaalp IS, Tummala PP, et al. The effect of valvular heart disease on maternal and fetal outcome of pregnancy. J Am Coll Cardiol 2001;37(3):893-899

29 Presbitero P, Prever SB, Brusca A. Interventional cardiology in pregnancy. Eur Heart J 1996;17(2):182-188

30 Greutmann M, Von Klemperer K, Brooks R, Peebles D, O’Brien P, Walker F. Pregnancy outcome in women with congenital heart disease and residual haemodynamic lesions of the right ventricular outflow tract. Eur Heart J 2010;31(14):1764-1770
31 Troost Els, Budts W. Risk of complications during pregnancy in women with congenital aortic stenosis. Euro Cardiovascular Disease 2007;391:108-110

32 Orwat S, Diller GP, van Hagen IM, et al; ROPAC Investigators. Risk of pregnancy in moderate and severe aortic stenosis: from the multinational ROPAC registry. J Am Coll Cardiol 2016;68(16):1727-1737

33 Meijer JM, Pieper PG, Drenthen W, et al. Pregnancy, fertility, and recurrence risk in corrected tetralogy of Fallot. Heart 2005;91(6):801-805

34 Veldtman GR, Connolly HM, Grogan M, Ammash NM, Warnes CA. Outcomes of pregnancy in women with tetralogy of Fallot. J Am Coll Cardiol 2004;44(1):174-180

35 Guédès A, Mercier LA, Leduc L, Bérubé L, Marcotte F, Dore A. Impact of pregnancy on the systemic right ventricle after a Mustard operation for transposition of the great arteries. J Am Coll Cardiol 2004;44(2):433-437

36 Tobler D, Fernandes SM, Wald RM, et al. Pregnancy outcomes in women with transposition of the great arteries and arterial switch operation. Am J Cardiol 2010;106(3):417-420

37 Connolly HM, Warnes CA. Ebstein's anomaly: outcome of pregnancy. J Am Coll Cardiol 1994;23(5):1194-1198

38 Chopra S, Suri V, Aggarwal N, Rohilla M, Vijayvergiya R, Keepanasseril A. Ebstein's anomaly in pregnancy: maternal and neonatal outcomes. J Obstet Gynaecol Res 2010;36(2):278-283

39 Donnelly JE, Brown JM, Radford DJ. Pregnancy outcome and Ebstein's anomaly. Br Heart J 1991;66(5):368-371

40 Therrien J, Barnes I, Somerville J. Outcome of pregnancy in patients with congenitally corrected transposition of the great arteries. Am J Cardiol 1999;84(7):820-824

41 Hornung TS, Bernard EJ, Celermajer DS, et al. Right ventricular dysfunction in congenitally corrected transposition of the great arteries. Am J Cardiol 1999;84(9):1116-1119, A10

42 Walker F. Pregnancy and the various forms of the Fontan circulation. Heart 2007;93(2):152-154

43 Peters NS, Somerville J. Arrhythmias after the Fontan procedure. Br Heart J 1992;68(2):199-204

44 Rosenthal DN, Friedman AH, Kleinman CS, Kopf GS, Rosenfeld LE, Hellenbrand WE. Thromboembolic complications after Fontan operations. Circulation 1995;92(9, Suppl):II287-II293

45 Drenthen W, Pieper PG, Roos-Hesselink JW, et al; ZAHARA Investigators. Pregnancy and delivery in women after Fontan palliation. Heart 2006;92(9):1290-1294

46 Galiè N, Hoeper MM, Humbert M, et al; ESC Committee for Practice Guidelines (CPG). Guidelines for the diagnosis and treatment of pulmonary hypertension: the Task Force for the Diagnosis and Treatment of Pulmonary Hypertension of the European Society of Cardiology (ESC) and the European Respiratory Society (ERS), endorsed by the International Society of Heart and Lung Transplantation (ISHLT). Eur Heart J 2009;30(20):2493-2537

47 Yuan SM. Eisenmenger syndrome in pregnancy. Rev Bras Cir Cardiovasc 2016;31(4):325-329

48 Jones AM, Howitt G. Eisenmenger syndrome in pregnancy. Br Med J 1965;1(5451):1627-1631

49 Weiss BM, Zemp L, Seifert B, Hess OM. Outcome of pulmonary vascular disease in pregnancy: a systematic overview from 1978 through 1996. J Am Coll Cardiol 1998;31(7):1650-1657 